\title{
Registered Nurses as Optimizers of Gender-Affirming Care Within a Transgender and Intersex Specialty Care Clinic
}

\author{
Alissa R. Zimmerman, MSN, RN, RN-BC (1) \\ Zachary C. Missel, RN, CCRN (1) \\ LeAnn M. Bauman, RN \\ Cesar A. Gonzalez, PhD, LP, ABPP (1)
}

\begin{abstract}
An estimated 1.4 million transgender adults live in the United States; this equates to approximately $0.6 \%$ of the U.S. population (Lane et al., 2018). Clinical focus on gender dysphoria has significantly increased over the past 30 years (MacCarthy, Reisner, Nunn, Perez-Brumer, \& Operario, 2015), with burgeoning evidence from across disciplines documenting the positive outcomes associated with gender-affirming interventions. The purpose of this article is to illustrate how RNs optimize psychosocial, hormonal, and surgical gender-affirming care through performing comprehensive assessments, coordinating care, and providing education and health coaching.
\end{abstract}

Keywords: transgender clinic; gender-affirming care; gender-affirming surgery; RNs

$A^{n}$ n estimated 1.4 million transgender adults live in the United States; this equates to approximately $0.6 \%$ of the U.S. population (Lane et al., 2018). As the evidence base for gender-affirming interventions has grown, so has social visibility and acceptance of transgender and gender-diverse people in the United States (Billard, 2016; Jones, Bouman, Haycraft, \& Arcelus, 2019). The term transgender describes individuals whose gender identity is incongruent with the sex assigned at birth (Human Rights Campaign, n.d.). The incongruence between gender identity and sex assigned at birth may lead individuals to experience clinically significant distress or impairment in functioning (Knudson, De Cuypere, \& Bockting, 2010). Clinical focus on gender dysphoria has significantly increased over the past 30 years (MacCarthy et al., 2015), with burgeoning evidence from across disciplines documenting the positive outcomes associated with gender-affirming interventions.

As the evidence base for gender-affirming interventions has grown, so has social visibility and acceptance of transgender and gender-diverse people in the United States (Billard, 2016; Jones et al., 2019). This positive transition reflects a growth in inclusivity, and is associated with an increased number of gender clinics and referrals around the world (Downing \&
Przedworski, 2018). Unfortunately, many clinics are challenged with long waiting lists, limiting access to care (Eade, Telfer, \& Tollit, 2018). The purpose of this article is to illustrate how RNs optimize genderaffirming care at a large, tertiary-care medical center in the Midwest, facilitating increased access and improved patient outcomes.

\section{HISTORY OF GENDER-AFFIRMING CARE}

The Transgender and Intersex Specialty Care Clinic (TISCC) is a multidisciplinary clinic serving individuals with gender dysphoria (Mayo Clinic, 2016). The TISCC was established in 2015 with a mission to "provide specialty, multidisciplinary, personaffirming care for transgender, gender-diverse and intersex individuals in a safe and respectful environment, while optimizing physical, emotional, and social health" (Mayo Clinic, 2016). The TISCC is rooted in the organization's mission "to inspire hope and contribute to health and well-being by providing the best care to every patient through integrated clinical practice, education and research" (Mayo Clinic, 2020).

The TISCC is the result of a collaborative effort by integrated health-care clinicians in social work, 
TABLE 1. Seeking Harmony With Gender Identity

\begin{tabular}{ll}
\hline Term & Definition \\
\hline Psychosocial congruence & $\begin{array}{l}\text { Changes of social identifiers such as clothing, hairstyle, gender identity, name, } \\
\text { and/or pronouns. Management of minority stress. }\end{array}$ \\
Hormonal congruence & $\begin{array}{l}\text { The use of medical approaches such as hormone blockers or cross-hormone } \\
\text { therapy to promote physical, mental, and/or emotional alignment. }\end{array}$ \\
Surgical congruence & The addition, removal, or modification of gender-related physical traits.
\end{tabular}

Source: Genderspectrum. (2020). Understanding gender. Retrieved from

https://www.genderspectrum.org/quick-links/understanding-gender/.

nursing, plastic surgery, endocrinology, psychiatry and psychology, laboratory medicine, and internal medicine, working together to help persons actualize a life in which they are affirmed in being who they are (Mayo Clinic, 2016). Standards of Care as defined by the World Professional Association for Transgender Health (WPATH, 2012) guide specialty practice as they facilitate the provision of care for transgender people to attain psychosocial, hormonal, and surgical congruence (see Table 1), which can ultimately result in a healthy, safe, and fulfilling life (National Center for Transgender Equality, 2016).

\section{EFFECTIVE NURSE-PATIENT RELATIONSHIPS}

RNs play a critical role in optimizing gender-affirming care. The TISCC leverages the patient-nurse relationship to promote positive patient outcomes (see Figure 1). Nurses are embedded throughout the continuum of care, promoting and providing culturally congruent, competent, safe, and ethical care (American Nurses Association, 2018). Nurses practice to the full extent of their scope, completing comprehensive assessments, developing and implementing evidence-based plans of care, and providing education and health coaching. This work promotes coordination across disciplines, enhances patient flow through the clinic, and

Clinical focus on gender
dysphoria has significantly
increased over the past 30 years,
with burgeoning evidence from
across disciplines documenting
the positive outcomes associated
with gender-affirming
interventions.

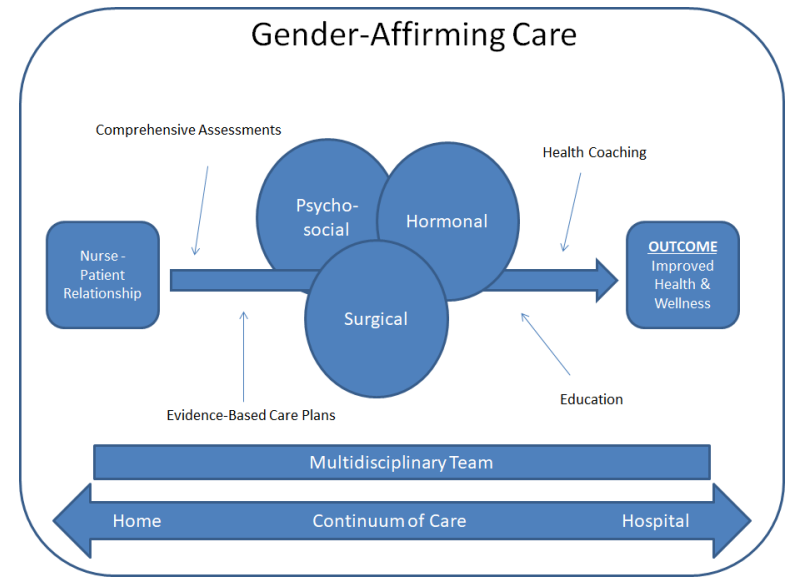

Figure 1. Outcome of nurse-patient relationship in delivering gender-affirming care.

ultimately affords the opportunity to serve more people and deliver improved outcomes.

\section{Comprehensive Assessments}

The patient's first interaction with the TISCC is through an intake phone call with an RN, which provides the individual an opportunity to speak freely, without concern for nonverbal cues of judgment or embarrassment. Although a structured screening assessment tool is utilized to assess vital health questions and develop a personalized care plan, the intake assessment quickly becomes conversational in nature (see Table 2). Ultimately, the goal of this interaction is to gain a better understanding of the individual's gender history, to discuss goals for coming to the TISCC, and to establish a trusted relationship in which the person feels affirmed and will continue to engage with care.

\section{Evidence-Based Care Plans}

Based on findings from the intake assessment, an RN helps coordinate follow-up visits with healthcare clinicians from the multidisciplinary team. 
TABLE 2. Intake Assessment Tool

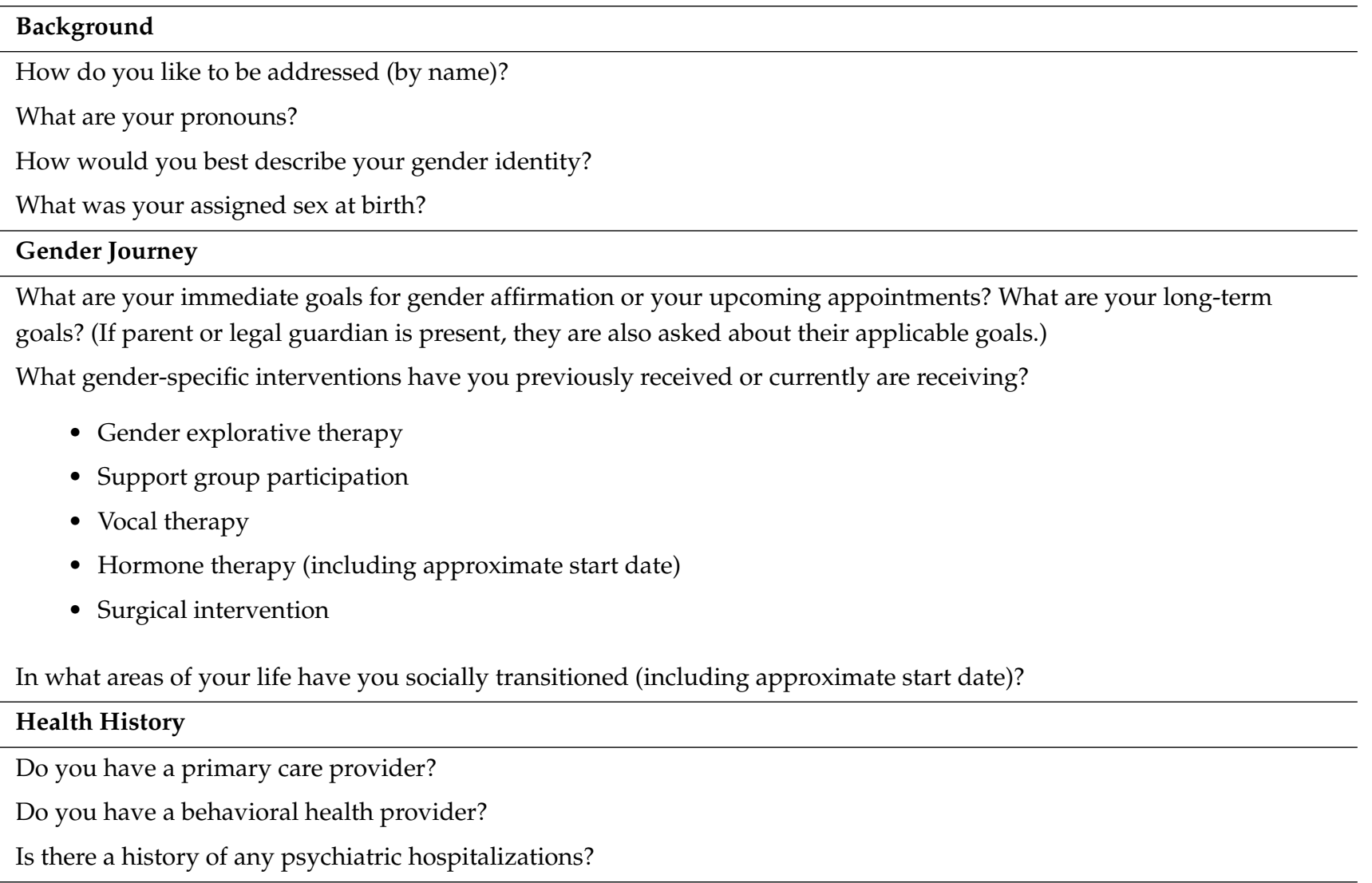

Outcome Optimization Screening for Hormones and/or Surgery

Calculate BMI:

- What is your most current weight?

- What is your height?

- Set expectations based on BMI requirements as defined by surgeon

Do you currently use any nicotine or tobacco products? Is there a history of use?

Do you currently use any cannabis products?

Preparation for Upcoming Appointments

Will anyone be attending your appointments with you?

Are they aware and supportive/affirming of your gender identity?

(If not legally changed) Would you like to have your affirmed name and pronouns noted in the medical record?

Appointments are made to suit the patient's schedule and to ensure that providers are seen in a systematic order. For patients who are seeking gender-affirming surgery, the RN supports discussion and review at a multidisciplinary care conference, during which time the RN provides a summary of the person's journey (see Table 3). Members of the multidisciplinary team discuss the individual's progress toward meeting the criteria set by WPATH's Standards of Care for genderaffirming surgery (2012), while the nurse ensures that all recommendations align with the patient's goals.
Based on the outcome of the discussion, arrangements are made either for a surgical consult or for health coaching and education to help the individual incorporate recommendations and optimize their care.

\section{Health Coaching and Education}

RNs provide health coaching as well as initial and ongoing education. Strategies focus on promoting holistic care to help individuals achieve optimal 
TABLE 3. Care Conference Participants

\begin{tabular}{|c|c|}
\hline Specialty & Role With Care Conference \\
\hline \multicolumn{2}{|l|}{ Endocrinology } \\
\hline $\begin{array}{l}\text { - Physician } \\
\text { - Physician's assistant } \\
\text { - } \mathrm{RN}\end{array}$ & $\begin{array}{l}\text { - Evaluates to ensure that } 12 \text { continuous months of hormone } \\
\text { therapy has occurred as appropriate for the patient's gen- } \\
\text { der goals unless clinically contraindicated. } \\
\text { - Evaluates medical status to ensure any significant medical } \\
\text { concerns are optimized prior to surgery. }\end{array}$ \\
\hline \multicolumn{2}{|l|}{ Surgery teams-Plastic, Gynecology, Urology } \\
\hline $\begin{array}{l}\text { - Surgeon } \\
\text { - } \mathrm{RN} \\
\text { - Secretary }\end{array}$ & $\begin{array}{l}\text { Ensures that all criteria for specific surgeries as outlined } \\
\text { by WPATH have been met and that the patient is a good } \\
\text { surgical candidate. } \\
\text { - Verifies all clinically relevant documentation has been } \\
\text { completed to best support insurance approval. }\end{array}$ \\
\hline \multicolumn{2}{|l|}{ Behavioral Health } \\
\hline $\begin{array}{l}\text { - Psychologists (consultants/clinical health } \\
\text { fellows) } \\
\text { - Psychiatry (residents/fellows) } \\
\text { - Licensed graduate/clinical social workers }\end{array}$ & $\begin{array}{l}\text { - Evaluates to ensure that if mental health concerns are } \\
\text { present, they are well controlled. } \\
\text { - Confirms that there is persistent, well-documented gender } \\
\text { dysphoria. } \\
\text { - Evaluates to ensure } 12 \text { continuous months of living in gen- } \\
\text { der role that is congruent with their gender identity. } \\
\text { - Evaluates social supports and perioperative plans to } \\
\text { ensure optimization. }\end{array}$ \\
\hline
\end{tabular}

Source: The World Professional Association for Transgender Health. (2012). Standards of care for the health of transsexual, transgender, and gender-nonconforming people. Journal of Transgenderism, 13(4). https://doi.org/10.1080/15532739.

\begin{tabular}{c}
\hline Although a structured screening \\
assessment tool is utilized to \\
assess vital health questions and \\
assist with the development and \\
personalization of a care plan, the \\
intake assessment quickly \\
becomes conversational in \\
nature.
\end{tabular}

gender-affirming therapies. Three examples across the continuum of care are psychosocial, hormonal, and surgical interventions.

Psychosocial Interventions. As individuals seek psychosocial congruence, RNs support them by helping them implement safe practices for achieving their goals for gender expression through nonmedical/surgical body affirming intervention, including assistive devices or practices to better align the patient's external appearance with their gender identity. Examples include binding (constricting of breast tissue for either a neutral or masculine shape), tucking (the practice of concealing the external genitalia for either a neutral or feminine shape), padding (use of padded garments to accentuate the hips or breasts), packing (use of plastic or fabric forms in the underwear for a more pronounced appearance of external genitalia), and various methods of hair removal. RNs are uniquely positioned to conduct physical head-to-toe assessments and provide education on safer and/or alternative methods of body affirmation that may reduce negative health impacts (e.g., skin alterations, and pain). 
TABLE 4. Surgical Interventions Performed

\begin{tabular}{|c|c|}
\hline Procedure & Description \\
\hline Breast augmentation (transfeminine) & $\begin{array}{l}\text { Also referred to as "top" surgery. Enhances the size and shape of the breasts to } \\
\text { create a more feminine appearance to the chest. }\end{array}$ \\
\hline $\begin{array}{l}\text { Breast reduction and creation of a } \\
\text { masculine chest (transmasculine) }\end{array}$ & $\begin{array}{l}\text { Also referred to as "top" surgery. Removes the breast tissue (mastectomy) } \\
\text { from both breasts t } 0 \text { create a more masculine appearance to the chest. }\end{array}$ \\
\hline Facial feminization & $\begin{array}{l}\text { Cosmetic and feminization procedures designed to transform the masculine } \\
\text { features of the face to a more feminine appearance. Procedures may include: } \\
\text { - Hairline advancement or forehead contouring } \\
\text { - Lip and cheek augmentation } \\
\text { - Rhinoplasty - changing the shape of the nose } \\
\text { - Chin reduction/recontouring } \\
\text { - Neck lift and face lift }\end{array}$ \\
\hline Hysterectomy & $\begin{array}{l}\text { Surgical procedure to remove the uterus. Can be performed in conjunction } \\
\text { with a salpingo-oophorectomy. }\end{array}$ \\
\hline Salpingo-oophorectomy & Surgical procedure to remove both the ovaries and fallopian tubes. \\
\hline Laser treatment & Removes areas of unwanted hair and decreases continued hair growth. \\
\hline Orchiectomy & Surgery in which one or both testicles are removed. \\
\hline Vaginoplasty & $\begin{array}{l}\text { Also referred to as "bottom" surgery. Surgical procedure that utilizes current } \\
\text { male tissue to create female genitalia. }\end{array}$ \\
\hline
\end{tabular}

Hormonal Interventions. The $\mathrm{RN}$ assesses the person's health literacy and ensures that they understand their individualized plan for hormone therapy. For hormones prescribed by parenteral route, patient handouts, videos, and live demonstration are used to promote effective subcutaneous and intramuscular administration techniques. At times, the RN may assist behavioral health clinicians with implementing exposure therapies to address specific medical phobias (e.g., needle phobia). Utilizing a teach-back process, return demonstration ensures understanding and promotes empowerment and confidence in selfadministering the therapy.

Surgical Interventions. While many transgender individuals are comfortable in their gender identity, role, and expression without surgery, for others it is essential and medically necessary to alleviate their gender dysphoria (Hage \& Karium, 2000). Congruence may be achieved through a single surgical procedure, or a series, depending on the individual's goals (see Table 4).

RNs assist patients throughout the surgical phases of care. In the preoperative stage, they provide important health coaching and education to ensure adherence to restrictions and expectations following surgery. Intraoperatively, nurses promote patient safety through effective positioning, as surgical procedures may take many hours. Postoperatively, nurses perform comprehensive assessments and promote optimal self-care through extensive education. Follow-up surgical care begins immediately after discharge, through electronic messaging and telephone interactions. In the clinic, nurse visits offer opportunities to reinforce education, assess the management of drainage tubes, and evaluate effectiveness of the plan of care.

\section{IMPROVED HEALTH AND WELLNESS}

RNs optimize care for transgender people through developing an effective nurse-patient relationship. They coordinate with the multidisciplinary team to assist the individual seeking psychosocial, hormonal, and/or surgical congruence. Through the implementation of comprehensive assessments, evidencebased care plans, health coaching, and education, the $\mathrm{RN}$ is able to assist transgender people with achieving improved health and wellness (De Cuypere et al., 2005).

\section{LESSONS LEARNED}

Each month the multidisciplinary TISCC team meets to discuss program successes and opportunities for 


\section{As individuals seek psychosocial congruence, RNs support them by helping them implement safe practices for achieving their goals for gender expression.}

improvement, new ways of approaching care, and ongoing professional development. The foundation for these discussions is always patient feedback and quality outcomes measures. Patient feedback is garnered through a series of intentionally designed formats:

- Patient satisfaction feedback gathered by a third-party vendor through randomized mailed surveys.

- Nurse leader rounding conducted by inpatient nurse managers using a series of questions designed specifically to engage patients in sharing their feedback about their health-care experience.

- Patient and Family Advisory Council is a council comprising patients and caregivers who have interacted with the TISCC. The council meets monthly to share perspectives, discuss opportunities for improvement, and implement strategies to enhance outcomes.

Lessons learned from the synthesis of patient feedback are shared with nursing staff across the continuum of care and are utilized to make action plans promoting continuous improvement. During the early phases of the TISCC, opportunities to enhance staff comfort, confidence, and resources were identified by both patients and staff. Education and training was developed in a variety of formats. Nursing grand rounds presentations that share clinical expertise and experiences were video-recorded for playback. and Online learning modules covering topics such as unconscious bias, patient rights, diversity and inclusion, and caring for gender-diverse patients have been developed and incorporated into the nursing orientation curriculum, and all nurse residents (newly graduated, newly licensed nurses in their first year of practice) receive didactic classroom teaching focused on strategies to promote inclusion. Recent feedback and experiences indicate that next steps are to explore ways to better partner with the community in providing resources and support to transgender individuals who may lack social support.

\section{CONCLUSION}

Nurses are committed to a holistic approach to patient care. As our society gains new understanding, it is important for those in our profession to intentionally prepare and respond to the health-care needs of our diverse patient population. The Institute of Medicine and the U.S. Department of Health and Human Services have called for a prioritization and focus on the health of LGBT persons (McDowell \& Bower, 2016). Although WPATH has not yet formally recognized the important role that $\mathrm{RNs}$ provide in optimizing genderaffirming care; transgender care clinics should leverage the $\mathrm{RN}$ role to optimize outcomes, improve access to care, and enhance health and wellness through comprehensive assessment, care coordination, education, and health coaching.

\section{REFERENCES}

American Nurses Association. (2018). ANA position statement: Nursing advocacy for LGBTQ+ for populations. The Online Journal of Issues in Nursing, 24(1), 1-5.

Billard, T. J. (2016). Writing in the margins: Mainstream news media representations of transgenderism. International Journal of Communication, 10, 4193-4218.

De Cuypere, G., T'Sjoen, G., Beerten, R., Selvaggi, G., De Sutter, P., Hoebeke, P., \& Rubens, R. (2005). Sexual and physical health after sex reassignment surgery. Archives of Sexual Behavior, 34(6), 679-690. https:/ / doi.org/10.1007/s10508-005-7926-5

Downing, J. M., \& Przedworski, J. M. (2018). Health of transgender adults in the US, 2014-2016. American Journal of Preventive Medicine, 55(3), 336-344. https://doi.org/10.1016/j.amepre.2018.04.045

Eade, D. M., Telfer, M. M., \& Tollit, M. A. (2018). Implementing a single-session nurse-led assessment clinic into a gender service. Transgender Health, 3(1), 45-47. https:/ / doi.org/10.1089/trgh.2017.0050

Genderspectrum. (2020). Understanding gender. Retrieved from https://www.genderspectrum.org/quick-links/ understanding-gender/

Hage, J., \& Karium, R. (2000). Ought GIDNOS get nought? Treatment options for nontranssexual gender dysphoria. Plastic and Reconstructive Surgery, 105(3), 1222-1227. https: / / doi.org/10.1097/00006534-200003000-00063

Human Rights Campaign. (n.d.). Understanding the transgender community. Retrieved from https://www.hrc.org/r esources/understanding-the-transgender-community

Jones, B. A., Bouman, W. P., Haycraft, E., \& Arcelus, J. (2019). Gender congruence and body Satisfaction in nonbinary transgender people: A case control study. International Journal of Transgenderism, 20(2-3), 263-274. https://doi.org/10.1080/15532739.2018.1538840

Knudson, G., De Cuypere, G., \& Bockting, W. (2010). Recommendations for revision of the DSM diagnoses of gender identity disorders: Consensus statement of the 
World Professional Association for Transgender Health. International Journal of Transgenderism, 12(2), 115-118. https: / / doi.org/10.1080/15532739.2010.509215

Lane, M., Ives, G. C., Sluiter, E. C., Waljee, J. F., Yao, T. H., Hu, H. M., \& Kuzon, W. M. (2018). Trends in gender-affirming surgery in insured patients in the United States. Plastic and Reconstructive Surgery. Global Open, 6(4), e1738. https://doi.org/10.1097/ GOX.0000000000001738

MacCarthy, S., Reisner, S. L., Nunn, A., Perez-Brumer, A., \& Operario, D. (2015). The time is now: Attention increases to transgender health in the United States but scientific knowledge gaps remain. LGBT Health, 2(4), 287291. https:/ / doi.org/10.1089/lgbt.2014.0073

Mayo Clinic. (2016). Addressing the challenges of transgender healthcare. Retrieved from https: / /www.mayoclinic.or $\mathrm{g} /$ medical-professionals/endocrinology/news/addre ssing-the-challenges-of-transgender-health-care/mac20429315

Mayo Clinic. (2020). Mayo clinic mission and values. Retrieved from https://www.mayoclinic.org/about-mayo-clinic /mission-values.

McDowell, A., \& Bower, K. M. (2016). Transgender health care for nurses: An innovative approach to diversifying nursing curricula to address health inequities. The Journal of Nursing Education, 55(8), 476-479. https: / / doi.org/10.3928/01484834-20160715-11

National Center for Transgender Equality. (2016). About transgender people. Retrieved from https://transeq uality.org/

The World Professional Association for Transgender Health. (2012). Standards of care for the health of transsexual, transgender, and gender-nonconforming people. Journal of Transgenderism, 13(4), 21-65. https:/ / doi.org/10.1080/15532739

Disclosure. The author(s) have no relevant financial interest or affiliations with any commercial interests related to the subjects discussed within this article.

Funding. The author(s) received no specific grant or financial support for the research, authorship, and/or publication of this article.
Correspondence regarding this article should be directed to Alissa R. Zimmerman at zimmerman.alissa@mayo.edu

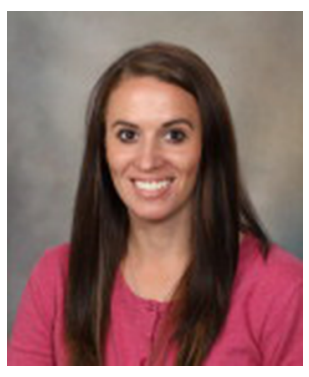

Alissa R. Zimmerman, MSN, RN, RN$\mathrm{BC}$, (she/her/hers) is an inpatient nurse manager for a General and Plastic Surgery unit at Mayo Clinic in Rochester, Minnesota.

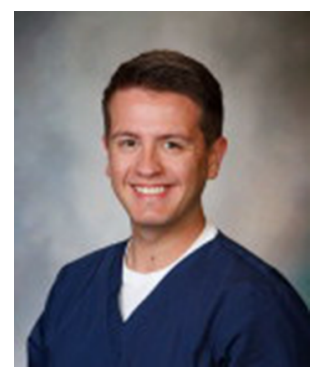

Zachary C. Missel, BSN, RN, CCRN, (he/him/his) works as an outpatient/ambulatory nurse supporting the Transgender and Intersex Specialty Care Clinic at Mayo Clinic in Rochester, Minnesota.

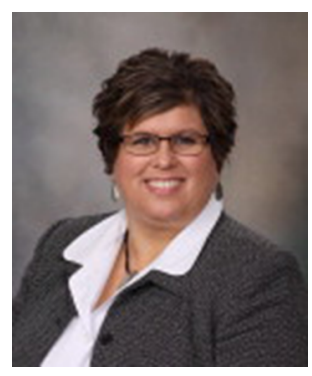

LeAnn M. Bauman, BSN, RN, (she/her/ hers) works as an outpatient/ambulatory nurse manager supporting General and Plastic Surgery care at Mayo Clinic in Rochester, Minnesota.

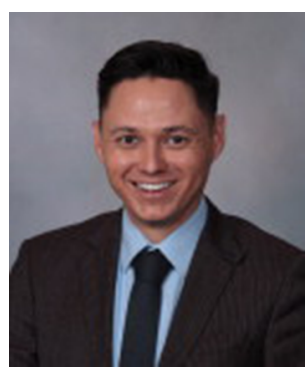

Cesar A. Gonzalez, PhD, LP, ABPP, (they/them, he/him) is a board-certified clinical psychologist and clinical director of the Transgender and Intersex Specialty Care Clinic at Mayo Clinic in Rochester, Minnesota. 